"This document is the Accepted Manuscript version of a Published Work that appeared in final form in ACS Catalysis, copyright (C) 2017 American Chemical Society after peer review and technical editing by the publisher. To access the final edited and published work see http://pubs.acs.org/doi/abs/10.1021/acscatal.7b01357

\title{
Kinetic Analysis of an Efficient Molecular Light-Driven Water Oxida- tion System
}

Laia Francàs, ${ }^{1,2}$ Roc Matheu, ${ }^{2}$ Ernest Pastor, ${ }^{1}$ Anna Reynal, ${ }^{1}$ Serena Berardi, ${ }^{2}$ Xavier Sala, ${ }^{3}$ Antoni Llobet $^{2,3^{*}}$ and James R. Durrant ${ }^{1}$

Addresses

1 Department of Chemistry, Imperial College London, South Kensington Campus, London, SW7 2AZ, United Kingdom.

2 Institute of Chemical Research of Catalonia (ICIQ), Avinguda Països Catalans 16, 43007 Tarragona, Spain.

3 Departament de Química, Universitat Autònoma de Barcelona, Cerdanyola del Vallès, o8193 Barcelona, Spain.
Commented [FFL1]: Please, can you add your current address in the end of the document

KEYWORDS: Light-driven catalysis, water oxidation, quantum yield, kinetics, oxygen generation.

ABSTRACT: We report a remarkably efficient molecular photocatalytic system to photoxidize water to oxygen and undertake a kinetic analysis of the factors determining system efficiency. The system comprises a highly active molecular catalyst $\left(\left[\mathrm{Ru}^{\mathrm{IV}}(\mathrm{tda})(\mathrm{py})_{2}(\mathrm{O})\right]\right),\left[\mathrm{Ru}^{\mathrm{III}}(\text { bpy })(\text { bpy-COOEt })_{2}\right]^{3+}$ as sensitizer and $\mathrm{Na}_{2} \mathrm{~S}_{2} \mathrm{O}_{8}$ as sacrificial electron acceptor. This combination exhibits remarkably high quantum yields $(25 \%)$ and chemical yields (96\%) for photo-driven oxygen evolution from water. The processes underlying this high performance are identified using optical techniques including transient absorption spectroscopy and photoluminescence quenching. A high catalyst concentration is found to be required to optimize the efficiency of electron transfer between the oxidized sensitizer and the catalyst, which also has the effect of improving sensitizer stability. The main limitation to system quantum efficiency is found to be the relatively low efficiency of $\mathrm{S}_{2} \mathrm{O}_{8}{ }^{2-}$ as an electron scavenger to oxidize $\mathbf{R u P}^{*}$ to $\mathbf{2} \mathbf{R u P}^{+}$, mainly due to competing back electron transfers to the $\mathbf{R u P}$ ground state. The overall rate of photocatalytic oxygen generation is found to be determined primarily by the rate of photon absorption by the molecular sensitizer under the incident photon flux. As such we conclude that the performance of this remarkably efficient photocatalytic system is limited not by the properties of the molecular water oxidation catalyst, which exhibits both excellent kinetics and stability, but rather by the light absorption and quantum efficiency properties of the sensitizer and electron scavenger. We conclude by discussing the implications of these results for further optimization of molecular photocatalytic systems for water oxidation.

\section{INTRODUCTION}

Harnessing solar energy to drive the synthesis of hydrogen from water, and the reduction of $\mathrm{CO}_{2}$ to other fuels such as methanol, offers a renewable, carbon neutral pathway to reduce our dependency on fossil fuels. This process is often called artificial photosynthesis, because it mimics plant's use of solar energy, water and $\mathrm{CO}_{2}$ to store energy in chemical bonds. As in natural photosynthesis, one of the key processes that need to take place is water oxidation, in which four electrons and four protons are extracted from two water molecules, producing molecular oxygen. This process is both kinetically and energetically demanding. A key challenge in this field is thus the development of suitable water oxidation catalysts that drive water oxidation induced by light. In recent years, substantial progress has been reported on molecular water oxidation catalysts ${ }^{1,2}$ although light driven water oxidation activity has been demonstrated in only a small number of cases. ${ }^{3,4,5,6,7,8,9,10,11}$ Furthermore for these photoactivated systems, analyses of the different kinetics processes that determine system efficiency have been very limited to date and in several cases the molecular catalyst has been reported to degrade to the corresponding oxide. ${ }^{3,6 b, 7,8,9 a}$.

Homogeneous photoactivated water oxidation systems typically consist of ternary systems including a light harvesting molecule such as $\left[\mathrm{Ru}(\mathrm{bpy})_{3}\right]^{2+}$ (bpy is 2,2'-bipyridine; see Chart 1 for a drawing), a sacrificial electron acceptor such as persulfate and a water oxidation catalyst. 
Amongst all the reported molecular water oxidation catalysts, Ruthenium complexes have been shown to exhibit the highest performances when driven both chemically and electrochemically. However such catalysts often exhibit rather poor efficiencies when used in photocatalytic systems, with quantum yields for oxygen generation per incident photon of typically $\leq 10 \% .3 .4 \mathrm{a}$ These modest efficiencies for photocatalytic systems have been previously often assigned to limitations associated with the low turnover frequencies (TOF) of the molecular water oxidation catalyst, as well as the severe overpotentials required to drive the catalytic reaction. As such, efforts in this field have been recently focused on improving both the overpotential requirements and TOF's for molecular water oxidation catalysts. It is worth mentioning here that increasing the catalyst-dye interactions via a supramolecular approach can also significantly enhance quantum yields. ${ }^{5}$

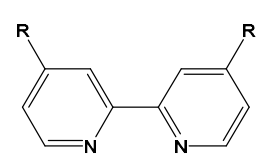

$\mathrm{R}=\mathrm{H}$ or COOEt

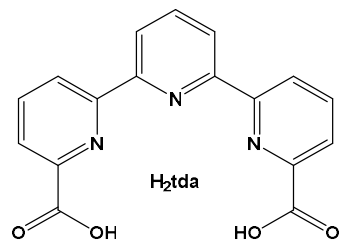

\section{Chart 1. Key ligands used in this work}

Recently we have reported a highly efficient $\mathrm{Ru}$ based water oxidation catalyst $\left[\mathrm{Ru}^{\mathrm{IV}}(\mathrm{tda})(\mathrm{py})_{2}(\mathrm{O})\right]$, (abbreviated from now on as $\mathbf{R} \mathbf{u}^{\mathrm{IV}}=\mathbf{O}$; py is pyridine and $\operatorname{tda}^{2-}\left[\mathbf{2}, \mathbf{2}^{\prime}: 6^{\prime}, \mathbf{2}^{\prime \prime}-\right.$ terpyridine]-6,6"-dicarboxylato; see Chart 1 ), that is generated in neutral or basic $\mathrm{pH}$ from its precursor $\left[\mathrm{Ru}^{\mathrm{IV}}(\mathrm{tda}-\kappa-\right.$ $\left.\mathrm{N}_{3} \mathrm{O}^{2}\right)(\text { py) })_{2}$ ], $\mathbf{R u}^{\mathbf{I V}}$-tda. The $\mathbf{R u}^{\mathbf{I V}}=\mathbf{O}$ complex oxidizes water to oxygen elecrocatalytically at $\mathrm{pH}=7$ with a maximum turnover frequency of $8,000 \mathrm{~s}^{-1}$. Thus we have decided to build a ternary photoactivated system with this catalyst involving a Ru-bpy like type of sensitizer and persulfate as a sacrificial electron acceptor. Here in we describe that this yields a remarkably efficient homogeneous light driven water oxidation system. We use electrochemical, steady state and transient spectroscopic techniques to study the key steps occurring in this 3 component systems that allows us to successfully present a consistent and detailed kinetic analysis of different reactions involved. Further we also analyze the different efficiencies involved in the key individual steps.

\section{RESULTS}

2.1 Dark redox processes for the Ru-tda molecular catalyst.

We first consider the dark redox chemistry of the molecular water oxidation catalyst employed in this study. Recently we have reported a family of Ru complexes containing the pentadentate ligand $\mathrm{tda}^{2-}$ that coordinates the metal center in the equatorial plane so that the remaining two axial coordination positons can be occupied by monodentate ligands such as pyridine. ${ }^{2}$ At oxidation state II the $\mathrm{tda}^{2-}$ ligand binds in a tetradentate manner, [ $\mathrm{Ru}^{\mathrm{II}}(\mathrm{tda}-\kappa-$ $\mathrm{N}^{3} \mathrm{O}$ )(py) $)_{2}$, labelled as $\mathbf{R} \mathbf{u}^{\mathrm{II}}$-tda (Scheme 1) but upon two successive one-electron oxidation the latter yields the seven coordinate complex $\left[\mathrm{Ru}^{\mathrm{IV}}\left(\mathrm{tda}-\kappa-\mathrm{N}^{3} \mathrm{O}^{2}\right)(\mathrm{py})_{2}\right], \mathbf{R u}^{\mathrm{IV}}-$ tda, where now the tda $^{2-}$ ligand acts in a pentadentate fashion as shown in the upper part of Scheme 1. The redox potentials of these complexes are outlined in the Scheme 1 and pure samples of these complexes can be obtained either chemically or electrochemically by bulk electrolysis and have been individually characterized. ${ }^{2}$ Chemically the oxidation can be achieved using $\mathrm{Ce}(\mathrm{IV})\left(\mathrm{E}^{\mathrm{o}} \mathrm{IV/III}=1.7 \mathrm{~V}\right.$ at $\mathrm{pH}$ $=1.0)^{12}$ or with $\left[\mathrm{Ru}(\mathrm{bpy})_{3}\right]^{3+}\left(E_{\mathrm{III} / \mathrm{II}}^{\mathrm{o}}=1.2 \mathrm{~V}\right)$. All potentials discussed in this work are reported $v s$. NHE.

In the present context, it is important to realize that persulfate acts as an oxidative reagent. Indeed, a $1 \mathrm{mM}$ solution of $\mathbf{R} \mathbf{u}^{\mathrm{II}}-\mathbf{t d a}$ is slowly oxidized to its $\mathrm{Ru}(\mathrm{III})$ species with a $100 \mathrm{mM}$ solution of $\mathrm{S}_{2} \mathrm{O}_{8}{ }^{2-}$ both at $\mathrm{pH}=7.0$ and at $\mathrm{pH}=1.0$ as shown in Figure 1 and the SI. On the other hand, under similar conditions $\mathbf{R} \mathbf{u}^{\mathbf{I V}}$-tda is slowly reduced to $\mathrm{Ru}(\mathrm{III})$ at $\mathrm{pH} 7$, as but is stable at $\mathrm{pH}=1.0$ (see SI text and Figure $\mathrm{S}_{1}$ for details).

Scheme 1. Ru-tda catalyst precursor at different oxidation sates and simplified catalytic water oxidation cycle proposed for $\left[\mathrm{Ru}^{\mathrm{IV}}(\mathrm{tda})(\mathrm{py})_{2}(\mathrm{O})\right], \mathrm{Ru}^{\mathrm{IV}}=\mathrm{O}$, at $\mathrm{pH}=$ $7^{2}$

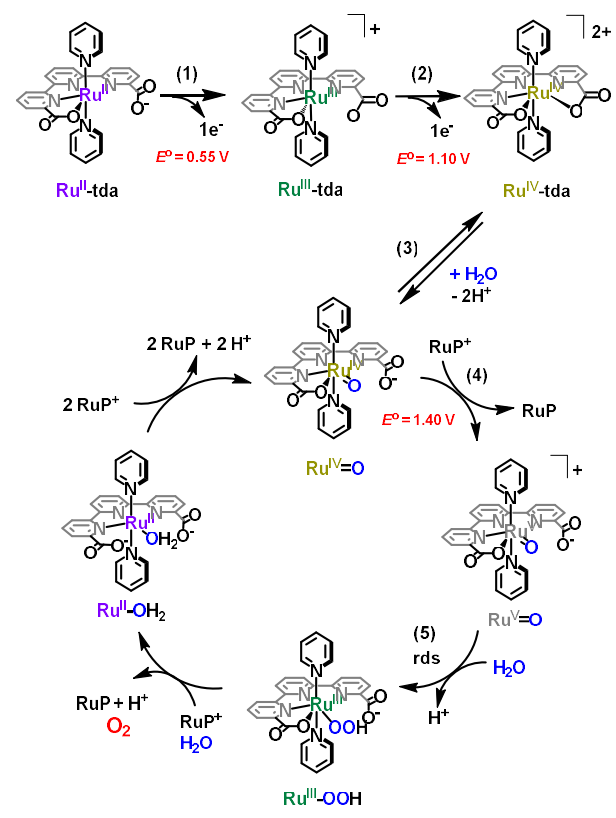

At $\mathbf{p H}=7$ the $\mathbf{R u}^{\mathbf{I V}}$-tda complex undergoes aquation to generate $\left[\mathrm{Ru}^{\mathrm{IV}}(\mathrm{tda})(\mathrm{py})_{2}(\mathrm{O})\right], \mathbf{R u}^{\mathrm{IV}}=\mathbf{O}$ (see equation 3 in Scheme 1), which we have demonstrated previously to be a remarkably efficient electrochemical water oxidation catalyst (WOC). The catalytic cycle followed by this complex 
has been described recently and a simplified reaction sequence is illustrated in Scheme $1 .^{2} \mathrm{~A}$ key step in this process is the oxidation of the $\mathbf{R} \mathbf{u}^{\mathrm{IV}}=\mathbf{O}$ complex to its $\mathbf{R} \mathbf{u}^{\mathrm{V}}=\mathbf{O}$ species which occurs electrochemically at $1.40 \mathrm{~V}$, followed by $\mathrm{O}-\mathrm{O}$ bond formation via a water nucleophilic attack (WNA) that generates the corresponding $\mathbf{R} \mathbf{u}^{\text {III }} \mathbf{O O H}$; this step is the rds of the whole catalytic cycle. ${ }^{2}$ A specific feature of this catalytic system is the equilibrium between the catalyst precursor (Ru-tda) species and those of the catalyst $\left(\mathbf{R u}-\mathbf{H}_{2} \mathbf{O}\right)$. For the light driven system reported herein, we found this equilibrium to be a function of the irradiation time (See SI). After 2 minute irradiation, as employed in our transient absorption measurements described below, cyclic voltammetry data indicates a ratio of [Ru$\mathbf{H}_{\mathbf{2}} \mathrm{O}$ ]:[Ru-tda] is 1:50; over long irradiation periods (1 hour) the ratio increases up to $2.6: 1$.

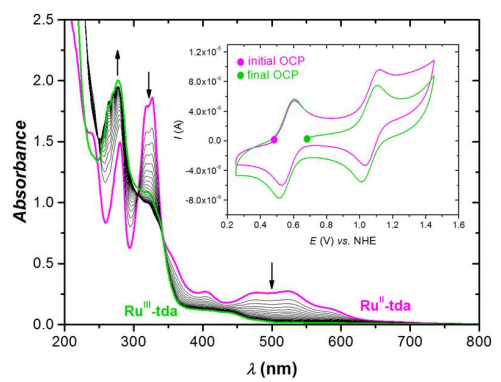

Figure 1. UV-Vis kinetic monitoring for the oxidation of $4 \mu \mathrm{M}$ $\mathbf{R u}^{\mathrm{II}}$-tda by $10 \mathrm{mM} \mathrm{S}_{2} \mathrm{O}_{8}{ }^{2-}$ in the dark in a 7-phbf. Pink trace, initial spectrum. Green trace final spectrum after 20 consecutive scans measured every 5' during 1 h. Inset, Cyclic Voltammetry and Open Circuit Potential measured before the addition of persulfate (pink trace) and after hour reaction time (green trace). Scan rate $=100 \mathrm{mV} / \mathrm{s}$. The arrow indicates the scan direction.

Chemically the key oxidation of $\mathbf{R} \mathbf{u}^{\mathrm{IV}}=\mathbf{O}$ to $\mathbf{R} \mathbf{u}^{\mathbf{V}}=\mathbf{O}$ cannot be accomplished with $\left[\mathrm{Ru}^{\mathrm{III}}(\mathrm{bpy})_{3}\right]^{3+}$ because its III/II redox potential is too low. However the carboxylic ester derivative $\left[\mathrm{Ru}^{\mathrm{III}}(\mathrm{bpy})(\mathrm{bpy}-\mathrm{COOEt})_{2}\right]^{3+}$ (bpy-COOEt, is $4,4^{\prime}$ ethyl ester dicarboxyalte-2,2'-bipyridine; see Chart 1), $\mathbf{R u P}^{+}$, has a $E^{\mathrm{o}}=1.62 \mathrm{~V}^{4 \mathrm{a}}$ and thus has the sufficient thermodynamic driving force to carry out such a transformation. Therefore $\mathbf{R u P}^{+}$can be potentially used do drive all the oxidation reactions involved in the catalytic cycle displayed in Scheme 1, and is employed in the study herein.

Finally it is important to bear in mind that at $\mathrm{pH}=1.0$ the aquation reaction (equation 3, Scheme 1) does not occur and thus at this $\mathrm{pH}$ the complex does not show any catalytic activity. ${ }^{2}$

2.2 Light Induced water oxidation catalysis

In order to carry out the light induced water oxidation catalysis we use the $\mathbf{R} \mathbf{u}^{\mathrm{IV}}=\mathbf{O}$ species described above as the catalyst (generated in situ from its $\mathbf{R} \mathbf{u}^{\mathrm{III}}$-tda precursor), driven by $\mathbf{R u} \mathbf{P}^{+}$generated from $\mathbf{R u P}$ with light irradiation in the presence of an excess of a sacrificial electron acceptor such as $\mathrm{S}_{2} \mathrm{O}_{8}{ }^{2-}$. For this purpose, initially we have done an optimization of the reaction conditions in the absence of catalyst.

2.2.1 Photochemical system optimization in the absence of water oxidation catalyst

Under irradiation conditions in the presence of $\mathrm{S}_{2} \mathrm{O}_{8}{ }^{2-}$, the generation of $\mathbf{R u P}^{+}$is described by the equations 1-4 shown in Table 1, where the efficiency definitions are also indicated. A schematic representation of these reactions is also illustrated in Scheme 2.

We proceeded to optimize this process based on steady state photoluminescence (PL) experiments following the quenching of the excited stated, $\mathbf{R u P}^{*}$, by persulfate (see equation 2, Table 1, also Figures $\mathrm{S}_{2}$ and $\mathrm{S}_{3}$ in the $\mathrm{SI}$ ). This quenching process has been widely studied in the literature for $\left[\mathrm{Ru}(\mathrm{bpy})_{3}\right]^{2+3,6,13}$, and is known to be a complex system due to the ionic pairing between the $\mathbf{R u P}^{+}$and the $\mathrm{S}_{2} \mathrm{O}_{8}{ }^{2-}$, which causes a linearity loss in the Stern Volmer plots (see Figure S2b in the SI) associated with the change in ionic strength in the medium. ${ }^{14}$ We found good conditions at $\mathrm{pH}=7.0$, using a $25 \mathrm{mM}$ phosphate buffer (from now on labelled as 7-phbf). These are thus the conditions that will be used throughout the present work unless explicitly mentioned. Under these conditions, a persulfate concentration range of $10-100 \mathrm{mM}$ gives quenching efficiencies $\phi_{\mathrm{q}}$ of $0.75-0.90$ respectively (See Table 1 for efficiency definitions and Fig $\mathrm{S}_{2}$ ).

Transient absorption spectroscopy allows investigation of the kinetic processes involved in the binary solution of $\mathrm{RuP}$ dye and $\mathrm{S}_{2} \mathrm{O}_{8}{ }^{2-}$, which has been widely studied for the $\left[\mathrm{Ru}(\mathrm{bpy})_{3}\right]^{2+}$ case. ${ }^{3,6,13,15}$ The change in absorbance of $\mathbf{R u P}$ in the presence of $\mathrm{S}_{2} \mathrm{O}_{8}{ }^{2-}$ after photoexcitation is characterized by a negative photobleach feature at wavelengths shorter than $600 \mathrm{~nm}$ and a positive photoinduced absorbance at the $650-800 \mathrm{~nm}$ region (See Figure $\mathrm{S}_{3}$ ), assigned to the photoinduced generation of $\mathbf{R u} \mathbf{P}^{+}$, by analogy with $\left[\mathrm{Ru}(\mathrm{bpy})_{3}\right]^{2+}$. These transient absorption signals decay with a half-life time $0.7 \mathrm{~s}$, as illustrated at $460 \mathrm{~nm}$ in Figure 2 (orange trace) and assigned to decay of photogenerated $\mathbf{R u P}{ }^{+}$species back to its ground state, RuP. The grow in of these $\mathbf{R u} \mathbf{P}^{+}$signals was observed to be biphasic, with an initial instrument response limited ( $<150 \mathrm{~ns})$ rise, followed by a slower $\left(\mathrm{t}_{1 / 2}=3.8 \mu \mathrm{s}\right)$ rise, as shown in Figure $\mathrm{S}_{4}$. Following an analogous study by Scandola and coworkers, 7 the initial rise is assigned to the direct oxidation of photogenerated $\mathbf{R u P}^{*}$ by $\mathrm{S}_{2} \mathrm{O}_{8}{ }^{2-}$ termed "direct oxidation" (eq. 2, Table 1 ), and the subsequent microsecond phase to diffusion limited oxidation of $\mathbf{R u P}$ by the radical $\mathrm{SO}_{4}{ }^{--}$to generate again $\mathbf{R u P}^{+}$, termed "dark oxidation" (eq. 3, Table $\mathbf{1}$ and Scheme 2). The efficiency of the dark oxidation relative to the preceding direct oxidation can be estimated from the relative amplitudes of these two phases, giving a value of $\phi_{\mathrm{d}}=0.6,3,7$ (see Table 1 for details). The combination of these TAS and PL experiments allow to calculate an overall quantum efficiency for the $\mathbf{R u P ^ { + }}$ generation, $\phi_{\mathrm{RuP}_{+}}=0.56$, that considers both the direct and dark processes (see Table 1 for definition), corresponding to the generation of 1.12 $\mathbf{R u P}^{+}$species per absorbed photon. 

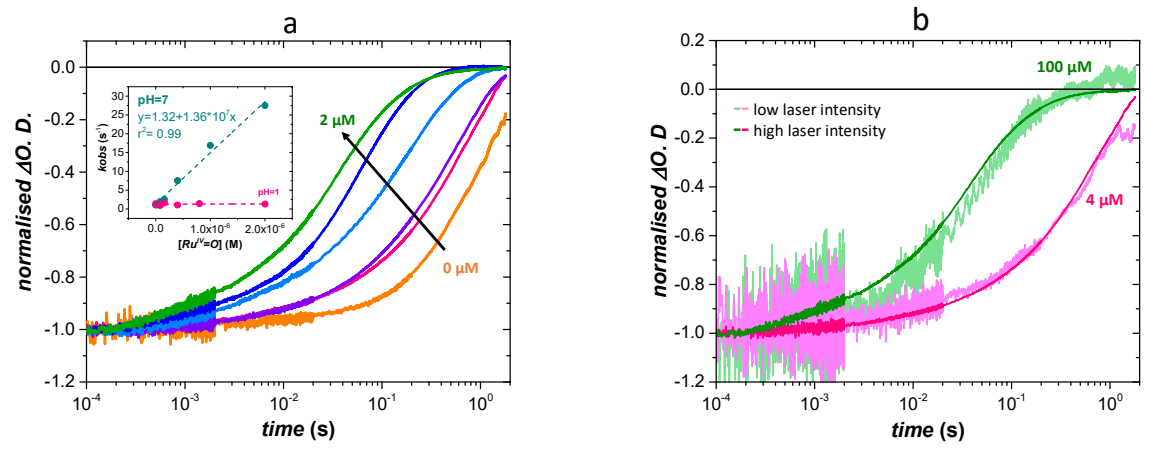

Figure 2. a, normalised TA decays at $460 \mathrm{~nm}\left(\lambda_{\mathrm{ex}}=500 \mathrm{~nm}\right.$; laser intensity $\left.=177.48 \mu \mathrm{J} \mathrm{cm}^{-2}\right)$ for a 7 -phbf solution containing a 20 $\mu \mathrm{M} \mathbf{R u P}, 10 \mathrm{mM} \mathrm{S}_{2} \mathrm{O}_{8}{ }^{2-}$ in the absence of catalyst (orange trace) and with different [ $\mathbf{R u}^{\mathbf{I V}}=\mathbf{O}$ ] (pink, $80 \mathrm{nM}$; purple, $160 \mathrm{nM}$; blue, $0.4 \mu \mathrm{M}$; dark blue, $1 \mu \mathrm{M}$, green $2 \mu \mathrm{M}$ ) that were generated from the corresponding [Ru-tda] precursors (see text). Data collected under $\mathrm{N}_{2}$ at $10 \mu \mathrm{s}-2 \mathrm{~s}$ timescales. Inset, plot of $k_{\mathrm{obs}} v s$. [Ru' $\left.\mathbf{R u}^{\mathrm{II}}-\mathbf{t d a}\right]$ at $\mathrm{pH} 7$ and $\mathrm{pH} 1$.

b, TAS decays measured at $460 \mathrm{~nm}$ under pulsed laser (pink) and $5 \mathrm{~s}$ LED irradiation $\left(15.4 \mathrm{~mW} \mathrm{~cm}^{-2}\right)$ (violet). Data shown for 20 $\mu \mathrm{M} \mathrm{RuP}, 10 \mathrm{mM} \mathrm{Na} \mathrm{S}_{2} \mathrm{O}_{8}$ and $40 \mu \mathrm{M} \mathrm{Ru} \mathbf{u}^{\mathrm{II}}$-tda that generates a $\left[\mathbf{R u}^{\mathrm{IV}}=\mathbf{O}\right]=0.8 \mu \mathrm{M}$. Inset, full linear timescale traces of the transient signal under LED excitation showing the change of both at light on and light off, in the absence (orange) and presence of o.8 $\mu \mathrm{M}$ $\mathbf{R} \mathbf{u}^{\mathrm{IV}}=\mathbf{O}$ (violet).

Table 1. Efficiencies of Light and Dark Reactions Studied.

\begin{tabular}{|c|c|c|}
\hline Process & Chemical Reaction & Eff. Def. \\
\hline Light absorption: & $\mathrm{RuP}+\mathrm{hu} \rightarrow \mathrm{RuP}^{*}$ & \\
\hline $\begin{array}{l}\text { Direct generation of } \\
\mathbf{R u P}^{+} \text {: }\end{array}$ & $\begin{array}{l}\mathrm{RuP}^{*}+\mathrm{S}_{2} \mathrm{O}_{8}^{2-}-> \\
\mathrm{RuP}^{+}+\mathrm{SO}_{4}^{2-}+\mathrm{SO}_{4}^{--}(2)\end{array}$ & $\phi_{\mathrm{q}}=1-\mathrm{I} / \mathrm{I}_{\mathrm{o}} \mathrm{a}$ \\
\hline $\begin{array}{l}\text { Dark generation of } \\
\text { RuP+: }^{+}\end{array}$ & $\mathrm{RuP}+\mathrm{SO}_{4}^{--}->\mathrm{RuP}^{+}+\mathrm{SO}_{4}^{2-}$ & $\phi_{d}=\frac{\Delta O \cdot D \cdot d}{\Delta O \cdot D \cdot l} b$ \\
\hline Overall rxs (1)-(3) & $\begin{array}{l}2 \mathrm{RuP}+\mathrm{hv}+\mathrm{S}_{2} \mathrm{O}_{8}^{2-}-> \\
2 \mathrm{RuP}^{+}+2 \mathrm{SO}_{4}^{2-}(4)\end{array}$ & $\phi_{R u P+}=\frac{1}{2}\left\{\phi_{q}\left(1+\phi_{d}\right)\right\}$ \\
\hline $\begin{array}{l}\text { Bimolecular electron } \\
\text { transfer }\end{array}$ & $\mathrm{RuP}^{+}+\mathrm{Ru}^{\mathrm{IV}}=\mathrm{O}->\mathrm{RuP}+\mathrm{Ru}^{\mathrm{V}}=\mathrm{O}$ & $\phi_{E T}=1-\frac{k_{0}}{k_{o b s}} \mathrm{c}$ \\
\hline $\begin{array}{l}\text { Measured oxygen } \\
\text { quantum yield }\end{array}$ & $2 \mathrm{H}_{2} \mathrm{O} \stackrel{\mathrm{h} v}{------->\mathrm{O}_{2}+4 \mathrm{H}_{+}+4 \mathrm{e}^{-}(6)}$ & $\phi_{O 2}=\frac{2 \times\left(O_{2} \text { molecules }\right)_{t}}{\text { Absorbed photons } \times \Delta t \times \text { Area }} d$ \\
\hline $\begin{array}{l}\text { Calculated oxygen } \\
\text { Quantum yield }\end{array}$ & & $\phi_{\text {Total }}=\phi_{\mathrm{RuP}_{+}}{ }^{*} \phi_{\mathrm{ET}}{ }^{*} \phi_{\mathrm{Cat}}$ \\
\hline
\end{tabular}

${ }^{a} \mathrm{I}$ and $\mathrm{I}_{0}$ are the photoluminescence intensities in the presence and absence of $\mathrm{S}_{2} \mathrm{O}_{8}{ }^{2-}$ respectively.

${ }^{\mathrm{b}} \Delta$ O.D.l, is the amplitude of the initial phase. $\Delta$ O.D.d, is the amplitude of the second phase (see Figure $\mathrm{S}_{4}$ ). ${ }^{12}$

${ }^{c} k_{0}=1 / t_{50 \%}$ with no Cat and $k_{o b s}=1 / t_{50 \%}$ with Cat.

$d$ This calculation assumes an ideal quantum efficiency of 2 photons per molecule of oxygen, accounting for the ideal generation of two $\mathbf{R u P} \mathbf{P}^{+}$per photon and four $\mathbf{R u P}^{+}$per oxygen molecule.

${ }^{\mathrm{d}} \phi$ Cat is the chemical efficiency of water oxidation by the catalyst, assumed herein to correspond to the Faradaic efficiency measured under electrochemical oxidation. For an ideal system 
2.2.2 System optimization in the presence of the water oxidation catalyst

Once the combination of RuP dye and sacrificial electron acceptor had been optimized and the main kinetic and spectroscopic parameters unveiled for this binary system, the next step involved the addition of the water oxidation catalyst into the system.

Figure 3 shows that, in the absence of persulphate, the emission spectrum of a $4 \mu \mathrm{M} \mathbf{R u P}$ is not quenched by the addition of $4 \mu \mathrm{M}$ of the catalyst precursor $\mathbf{R} \mathbf{u}^{\mathrm{II}}$-tda in a 7phbf solution (orange). However when a solution of $10 \mathrm{mM}$ persulfate is added to the $\mathbf{R u P} / \mathbf{R} \mathbf{u}^{\mathrm{II}}$-tda solution, the emission is quenched by $60 \%$, basically independent of the catalyst concentration $\left(\phi_{\mathrm{q}}\right.$ as a function of $\left[\mathrm{S}_{2} \mathrm{O}_{8}{ }^{2-}\right]$ in the presence of catalyst is presented in Figure $\mathrm{S}_{5}$ ). Under identical conditions in the absence of $\mathbf{R} \mathbf{u}^{\mathrm{II}}-\mathbf{t d a}, \phi_{\mathrm{q}}=0.75$, indicating that in the former case the presence of the Ru catalyst reduces the efficiency of the electron scavenging, possibly due to additional deactivation pathways. With $\phi_{\mathrm{q}}=$ o.6o then the overall quenching efficiency for the generation of $\mathbf{R u P} \mathbf{P}^{+}$is, $\phi_{\mathrm{RuP}+}=0.50$ (i.e.: one $\mathbf{R u P} \mathbf{P}^{+}$per photon absorbed).

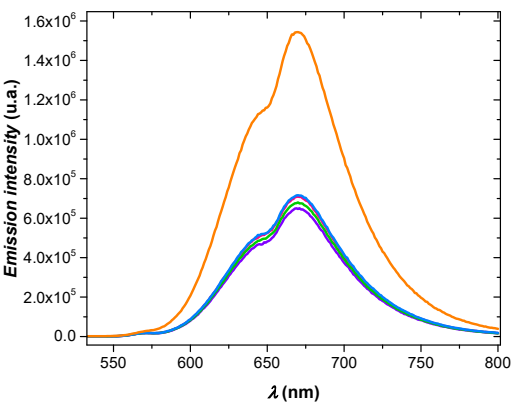

Figure 3. Emission spectra of a $4 \mu \mathrm{M} \mathbf{R u P}$ and $4 \mu \mathrm{M} \mathbf{R} \mathbf{u}^{\mathrm{II}}$-tda (orange) in the absence of sacrificial electron acceptor. Emission spectra of $4 \mu \mathrm{M} \mathbf{R u P}, 10 \mathrm{mM} \mathrm{Na} \mathrm{S}_{2} \mathrm{O}_{8}$ and different $\mathbf{R u}^{\mathrm{II}_{-}}$ tda concentrations (purple, $2 \mu \mathrm{M}$; pink, $4 \mu \mathrm{M}$; green, $6 \mu \mathrm{M}$; blue, $8 \mu \mathrm{M}$ ) all in a 7-phbf solution.

2.2.3 Kinetic characterization of light induced reaction with the complete system.

Transient absorption spectroscopy with the complete system involving dye, sacrificial electron acceptor and water oxidation catalyst was carried out in order to investigate the kinetic processes involved. All TAS measurements were performed after a 2 minute sample irradiation in order to equilibrate all the species in solution and thus measured under steady state catalytic conditions. Under these conditions, the catalyst precursor equilibrates with the active catalytic species (see equation 3 in Scheme 1 ). The relative concentrations were estimated to be $50: 1 \mathbf{R u}^{\mathrm{IV}}-\mathbf{t d a}: \mathbf{R} \mathbf{u}^{\mathrm{IV}}=\mathbf{O}$ , after 2 minute irradiation, as discussed above (see Figure
S6 in the SI). The well behaved kinetic analysis shown in Figure 2a inset supports the extrapolation of this ratio at different precursor concentrations. However with low intensity irradiation the catalyst concentration might be even lower.

Figure 2 shows the $\mathbf{R u P} \mathbf{P}^{+}$bleach signal decay kinetics at $460 \mathrm{~nm}$ in the presence of $\mathrm{Na}_{2} \mathrm{~S}_{2} \mathrm{O}_{8}$ as a function of catalyst precursor $\mathbf{R} \mathbf{u}^{\mathrm{II}}$-tda concentration in a 7-phbf solution. The decay kinetics observed in the TAS experiments correspond to the slowest ET transfer step (equation 4, Scheme 1), that is a bimolecular interaction between $\mathbf{R} \mathbf{u}^{\mathrm{IV}}=\mathbf{O}$ and $\mathbf{R u P}^{+}$. As can be seen in Figure 2, the decay kinetics accelerate with increasing catalyst concentration. The halftimes of these decays fitted well with a simple bimolecular expression with a reaction time linearly dependent on the catalyst concentration. This is in agreement with a pseudofirst order behavior where the $\left[\mathbf{R} \mathbf{u}^{\mathrm{IV}}=\mathbf{O}\right] \gg>\left[\mathbf{R} \mathbf{u} \mathbf{P}^{+}\right]$, and thus $\mathrm{k}_{\mathrm{ET}}$ can be extracted from the plot of $\mathrm{k}_{\mathrm{obs}} v s$. $\left[\mathbf{R u}^{\mathbf{I V}}=\mathbf{O}\right]$ as shown in the inset of Figure $\mathbf{2}$ and described in equations $5 \mathrm{a}-5 \mathrm{c})$.

$$
\begin{aligned}
& v=\mathrm{k}_{\mathrm{ET}}\left[\mathrm{Ru}^{\mathrm{IV}}=\mathrm{O}\right]\left[\mathrm{RuP}^{+}\right] \quad(5 \mathrm{a}) \\
& {\left[\mathrm{Ru}^{\mathrm{IV}}=\mathrm{O}\right] \gg>\left[\mathrm{RuP}^{+}\right] ; \mathrm{k}_{\text {obs }}=\mathrm{k}_{\mathrm{ET}}\left[\mathrm{Ru}^{\mathrm{IV}}=\mathrm{O}\right] \quad(5 \mathrm{~b})} \\
& v=\mathrm{k}_{\text {obs }}\left[\mathrm{RuP}^{+}\right] \quad(5 \mathrm{c})
\end{aligned}
$$

This gives a $k_{\mathrm{ET}}=1 \cdot 4 \cdot 10^{7} \mathrm{M}^{-1} \mathrm{~s}^{-1}$. Further evidence that confirms this assumption comes from the transient absorption decays using laser intensities of 180 and $20 \mu \mathrm{J} / \mathrm{cm}^{2}$ that are shown in Figure 4. These experiments generate different concentration of $\mathbf{R u P}^{+}$depending on the energy used but the normalized bleach kinetics is independent of $\left[\mathbf{R u P}^{+}\right]$, consistent with the pseudo-first order behavior indicated in the suite of equations $5 \mathrm{a}-5 \mathrm{c}$

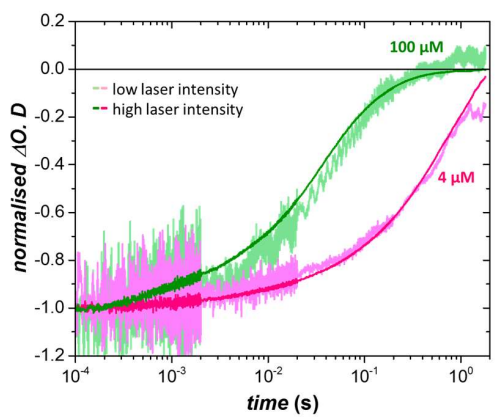

Figure 4. Normalized transient absorption decays at $460 \mathrm{~nm}$ of a $20 \mu \mathrm{M} \mathrm{RuP}, 10 \mathrm{mM} \mathrm{Na}{ }_{2} \mathrm{~S}_{2} \mathrm{O}_{8}$ and two $\mathbf{R u}^{\mathrm{IV}}=\mathbf{O}$ concentrations (purple, $80 \mathrm{nM}$; green, $2 \mu \mathrm{M}$ ) in a 7-phbf solution. Data collected under $\mathrm{N}_{2}$ at a $10 \mu \mathrm{s}-2 \mathrm{~s}$ timescale after dye excitation $\left(\lambda_{\text {ex }}=500 \mathrm{~nm}\right)$, using two different laser intensities of 180 (dark) and 20 (light) $\mu \mathrm{Jm}^{-2}$. 
The quantum efficiency of the oxidation of $\mathbf{R} \mathbf{u}^{\mathbf{I V}}=\mathbf{O}$ by $\mathbf{R u P}^{+}, \phi E \mathrm{E}$, can be estimated from the acceleration of the $\mathbf{R u P}^{+}$bleach decays (Figure 2a) at different catalyst concentrations (see Table 1). This gives $\phi_{\mathrm{ET}}$ values that range

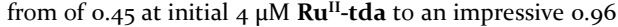
at $100 \mu \mathrm{M}$ as is discussed further below.

Furthermore, Photoinduced Absorbance (PIA) experiments were undertaken on the same experimental system employed in Figure 2a, using quasi-steady state irradiation achieved by $5 \mathrm{~s} 365 \mathrm{~nm}$ LED (light emitting diode) excitation pulses; the results are shown in Figure $2 \mathrm{~b}$. The inset shows full time traces measuring the $\mathbf{R u} \mathbf{P}^{+}$bleach signal in the presence and absence $\mathbf{R} \mathbf{u}^{\mathbf{I V}}=\mathbf{O}$. In the absence of catalyst, a $\mathbf{R u P} \mathbf{P}^{+}$bleach signal is observed, with a rise and fall times of $\sim 1 \mathrm{~s}\left(\mathrm{t}_{50} \%\right)$, assigned to the accumulation of oxidized $\mathbf{R u P} \mathbf{P}^{+}$under these quasi steady state conditions. The rise and fall times $\left(t_{50 \%}\right)$ of $\sim 1$ are consistent with $\mathbf{R u P} \mathbf{P}^{+}$ lifetime observed under laser excitation in the absence of catalyst (Figure 2a). In the presence of the $\mathbf{R} \mathbf{u}^{\mathbf{I V}}=\mathbf{O}$ catalyst, the LED irradiation resulted in a faster $\mathbf{R u} \mathbf{P}^{+}$bleach rise and decay due to electron transfer between the dye and catalyst. The decay kinetics of the $\mathbf{R u P}^{+}$bleach signal, monitored at LED turn off, and assigned to the oxidation of $\mathbf{R} \mathbf{u}^{\mathbf{I V}}=\mathbf{O}$ under these quasi-steady state conditions, are shown in the main part of Figure $2 b$ (violet trace) and are strikingly similar to those one obtained under short pulse laser excitation (pink trace). These experiments support our previous assumption that the TAS experiments are indeed already under steady state conditions. In addition, a

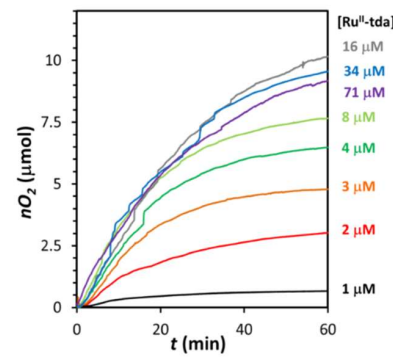

similar PIA experiment was carried out using a Clark electrode to simultaneous measure $\mathrm{O}_{2}$ formation, confirming the mentioned steady state situation (see Figure $\mathrm{S}_{7}$ ).

Similar experiments were carried out at $\mathrm{pH}=1.0$, where the equation described in reaction 3 in Scheme 1 does not occur. Thus at this $\mathrm{pH}$ under steady state conditions the catalyst precursor is oxidized to its higher oxidation states $\mathbf{R u}^{\mathrm{IV}}-\mathbf{t d a}$ but no further reactions occur since no catalytic species can be generated. ${ }^{2}$ In agreement with this, the bleach kinetics ( $\mathrm{k}_{\mathrm{obs}}$ ) were observed to be independent of the catalyst precursor concentration, as can be observed in the inset of Figure 2a (see also Figure S9). This is a key result that further supports our discussion above that at $\mathrm{pH}$ $\mathbf{1}$, light irradiation (such as the $\mathbf{2}$ minute light equilibration time employed prior to our TAS measurements) results in the initial catalyst precursor at oxidation state II being completely driven to its oxidation state IV species $\mathbf{R} \mathbf{u}^{\mathbf{I V}}$ tda, with this species being unable to undergo further oxidation by $\mathbf{R u} \mathbf{P}^{+}$.

2.3 Photocatalytic $\mathrm{O}_{2}$ generation

With this information associated with the quasi-steady state irradiation conditions, we were in a position to design steady state experiments for light induced water oxidation using $\mathbf{R u P}$ as photosensitizer, $\mathbf{R} \mathbf{u}^{\mathrm{II}}$-tda as a water oxidation catalyst precursor and persulfate as sacrificial electron acceptor in a 7-phbf solution. Figure 5 shows the oxygen evolution profiles as a function of time during one hour of irradiation, measured with a gas phase Clark electrode, for different Ru-tda concentrations ranging from 1-90 $\mu \mathrm{M}$ in the presence of $10 \mathrm{mM}$ persulfate and $200 \mu \mathrm{M} \mathrm{RuP}$ at 7phbf.
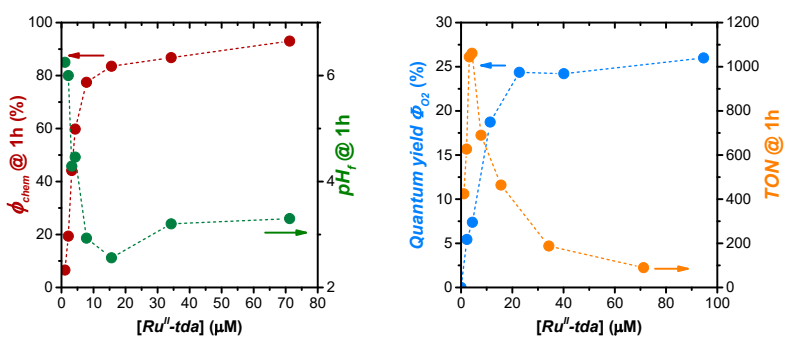

Figure 5. Bulk oxygen evolution experiments measured in the liquid phase during $1 \mathrm{~h}$ irradiation ( 1 sun) at different [Ru $\mathbf{u}^{\mathrm{II}}$-tda] (black, $1 \mu \mathrm{M}$; red, $2 \mu \mathrm{M}$; orange, $3 \mu \mathrm{M}$; dark green, $4 \mu \mathrm{M}$; light green, $8 \mu \mathrm{M}$; grey, $16 \mu \mathrm{M}$; blue, $34 \mu \mathrm{M}$, purple, $71 \mu \mathrm{M}$ ) containing the following $\mathrm{Na}_{2} \mathrm{~S}_{2} \mathrm{O}_{8}$ concentration: black, $9.9 \mathrm{mM}$; red $9.9 \mathrm{mM}$; orange, $10.9 \mathrm{mM}$; dark green, $10.9 \mathrm{mM}$; light green, $9.9 \mathrm{mM}$, grey, $12.4 \mathrm{mM}$; blue, $10.7 \mathrm{mM}$ and purple, $10 \mathrm{mM}$ and $0.2 \mathrm{mM} \mathrm{RuP}$ in a $2 \mathrm{~mL}$ 7-phbf solution. (a) Oxygen evolution $v s$. time. (b) Chemical efficiency (red) and final $\mathrm{pH}_{\mathrm{f}}$ (green) vs. [ $\left.\mathbf{R u}^{\mathrm{II}}-\mathbf{t d a}\right]$ that after one hour irradiation is partially converted to the catalyst giving a final ratio $\left[\mathbf{R u}^{\mathrm{IV}}=\mathbf{O}\right] /\left[\mathbf{R u}^{\mathrm{II}}-\mathbf{t d a}\right]=\mathbf{2 . 5}$, see SI. (c) Initial Quantum yield $\left(\phi_{\mathrm{O}_{2}}\right)$ (turquoise) and TONs (orange) based on the final $\left[\mathrm{Ru}^{\mathrm{IV}}-=\mathbf{O}\right]$. 
Figure $5 \mathrm{~b}$ shows a plot of the chemical efficiency, $\phi_{\mathrm{chem}}$, defined as ( $2 \mathrm{x}$ moles of oxygen generated/ moles of persulfate added) $\mathrm{x} 100$. It is interesting to see how increasing the $\mathbf{R} \mathbf{u}^{\mathrm{II}}$-tda concentration from $\mathbf{1}$ to $16 \mu \mathrm{M}$ increases $\phi_{\text {Chem }}$ from 7 to $80 \%$ respectively. Upon further increase of $\mathbf{R} \mathbf{u}^{\mathrm{II}}$ tda concentration, the chemical efficiency levels off reaching about $96 \%$ at $90 \mu \mathrm{M}$. This result shows that for this system at high catalyst concentrations, the overall amount of oxygen generated is limited only by the amount of sacrificial electron donor added to the solution, confirming the high efficiency and stability of the catalyst under the present conditions. Indeed it is also impressive to see that the system achieves a value of 1050 turn overs per hour with 8 $\mu \mathrm{M} \mathbf{R} \mathbf{u}^{\mathrm{II}}$-tda concentration that ranks among the most efficient light induced molecular water oxidation catalysts reported. ${ }^{3-4}, 6-11$

The low chemical efficiency at low catalyst concentrations is consistent with the lower quantum efficiency for catalyst oxidation by $\mathbf{R u P}^{+}\left(\phi_{\mathrm{ET}}\right)$ determined from our transient absorption data above, and indicates that competing deactivation pathways become important. The main deactivation processes for $\mathbf{R u P}^{+}$are likely to be associated with bpy-based oxidation of the $\mathbf{R u P}$ dye by the $\mathbf{R u P}^{+}$species as well as by the radical $\mathrm{SO}_{4}{ }^{-}$species, as has been previously proposed for related systems. ${ }^{15}$ These deactivation pathways also result in significant dye degradation, apparent from progressive photobleaching of the dye optical absorption, which was most pronounced at low catalyst concentrations. (see Figure S12 in the SI). $4^{a, 15}$

During the photocatalytic experiments, as oxygen is released four protons are generated per molecule of oxygen and thus even under a buffered solution the $\mathrm{pH}$ significantly decreases, as shown graphically in Figure 5 b. The $\mathrm{pH}$ decrease can alter the rates of electron transfer as well as the equilibrium of equation 3 (Scheme 1 ) that are responsible for the generation of the active species. It thus can significantly influence the delicate balance among the different chemical reactions involved in this complex process.

Quantum efficiencies for oxygen generation, $\phi_{\mathrm{O}_{2}}$, were calculated based on the initial rates of oxygen formation and the density of photons absorbed per second as indicated in Table 1 and the SI, and displayed in Figure $5 \mathrm{c}$ as a function of catalyst precursor concentration. As can be observed in this Figure, $\phi_{\mathrm{O}_{2}}$ increases with increasing [ $\mathbf{R u}^{\mathrm{II}_{-}}$ tda] and closely parallels that of $\phi_{\text {Chem. }}$ However while for the latter we reach values close to $100 \%$, for the former it

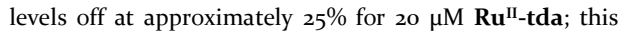
photon to oxygen quantum efficiency still constitutes the highest efficiency reported to date for this type of molecular photochemical water oxidation systems. We note our calculation of $\phi_{\mathrm{O}_{2}}$ assumes, conservatively, that each absorbed photon can optimally generate two $\mathbf{R u P}^{+}$and therefore that $\phi_{\mathrm{O}_{2}}=100 \%$ would correspond to one molecule of $\mathrm{O}_{2}$ per two photons. The factors still limiting this impressive quantum efficiency will be discussed below.

$$
\text { 3. DISCUSSION }
$$

We have demonstrated that the proper combination of a dye, $\mathbf{R u P} \mathbf{P}^{+}$, a water oxidation catalyst, $\mathbf{R} \mathbf{u}^{\mathrm{IV}}=\mathbf{O}$ and persulfate as sacrificial electron acceptor can constitute a photocatalytic system with unprecedentedly high chemical $\left(\phi_{\text {Chem }}=96 \%\right)$ and quantum $\left(\phi_{\mathrm{O}_{2}}=25 \%\right)$ efficiencies, for the light induced oxidation of water to molecular oxygen. This is achieved thanks primarily to the high stability and extremely fast water oxidation kinetics associated with the $\mathbf{R} \mathbf{u}^{\mathrm{IV}}=\mathbf{O}$ catalyst. The latter is generated in situ from the $\mathbf{R} \mathbf{u}^{\mathrm{II}}$-tda catalyst precursor under irradiation conditions. Both catalyst and catalyst precursor remain in equilibrium during the steady state oxygen formation under which the transient absorption spectroscopic measurements are carried out in the present work. Under these conditions we can measure the rate constant for electron transfer from $\mathbf{R u P} P^{+}$to $\mathbf{R u}^{\mathrm{IV}}=\mathbf{O}$ to be $k_{\mathrm{ET}}=1.4 \cdot 10^{7} \mathrm{M}^{-1} \mathrm{~s}^{-1}$. This rate constant is obtained based on a simple kinetic model assuming a pseudo-first order regime where $\left[\mathbf{R u P}^{+}\right]<<\left[\mathbf{R u}^{\mathbf{I V}}=\mathbf{O}\right]$. This is further corroborated by identical kinetic decay of samples irradiated with lasers of different intensity (See Figure 4). Similar kinetics were also obtained from quasi-steady state irradiation conditions (Figure 2b). Finally an indirect additional support is obtained based on the unchanged kinetics at $\mathrm{pH}=1.0$ with different catalyst concentrations, $\mathrm{pH}$ conditions under which the catalyst is trapped in its inactive $\mathbf{R u}^{\mathrm{IV}}$-tda state. The value of $k_{\mathrm{ET}}$ obtained here is one to two orders of magnitude slower than for related systems with polyoxometalate complexes reported in the literature, $3,7 \mathrm{z}, 8$ However in these cases there is no proof of oxygen formation during the time scale of the measurements and therefore it is probably related to the oxidation of an intermediate at low oxidation states, that are known to be much faster. $^{16}$

Scheme 2 summarizes the main reactions occurring in the present system including the kinetics of each individual step. Once the $\mathbf{R u P}^{*}$ is generated then all the main productive process involved in the generation of $\mathrm{O}_{2}$ occur within the time scale of ns to $\mathrm{ms}$, including oxidation of the water oxidation catalyst. This molecular water oxidation catalyst exhibits both exceptional stability and the potential to drive water oxidation with a TOF of up to 8,00o s ${ }^{-1}$. These very favorable light driven kinetics and catalyst characteristics are presumably responsible for the record high quantum yields obtained here.

The quantum efficiency for oxygen evolution $\phi_{\mathrm{O}_{2}}$ corresponds to the efficiency with which our photocatalytic systems utilizes absorbed photons to drive water oxidation, and is therefore a key measure of the efficiencies of the molecular processes determining system function. The three main processes involved in this photocatalytic function, as depicted in scheme 2, correspond: (1) $\mathbf{R u P}^{+}$generation with a quantum efficiency of $\phi_{\mathrm{RuP}+}$ (determined per $0.5 \mathrm{ab}$ sorbed photons, as discussed above), (2) electron transfer between $\mathbf{R u P}^{+}$and $\mathbf{R} \mathbf{u}^{\mathbf{I V}}=\mathbf{O}$ under constant illumination, with a quantum efficiency of $\phi_{\mathrm{ET}}$ and (3) water oxidation by the oxidized catalyst to yield molecular oxygen generation, with an efficiency of $\phi_{\text {CAT. }}$ The efficiencies $\phi_{\text {RuP+ }}$ and $\phi_{\mathrm{ET}}$, determined from our kinetic analyses above, are plotted in Figure 6 as a function of $\mathbf{R} \mathbf{u}^{\mathrm{II}}$-tda concentration. For $\phi_{\text {CAT, }}$ 
we assume a value of $92 \%$, determined from the faradaic efficiency of this catalyst under electrocatalytic system (see further discussion below). ${ }^{2}$ This figure furthermore includes a plot of the overall system quantum efficiency calculated from these three separate efficiencies: $\phi_{\text {TOTAL }}=$ $\phi_{\mathrm{RuP}_{+}}{ } \phi_{\mathrm{ET}} * \phi_{\mathrm{CAT}}$ as well as the directly measured quantum efficiency for oxygen evolution $\phi_{\mathrm{O}_{2}}$. It is apparent from Figure 6 that the quantum yields of oxygen evolution measured directly from oxygen concentration measurements
$\left(\phi_{\mathrm{O}_{2}}\right)$ show similar behaviour to those calculated from our kinetic analyses $\left(\phi_{\text {TотАL }}\right)$. Our calculated maximal quantum yield is in reasonable agreement with our measured one, differing by $18 \%$ (we discuss the origin of this difference below). As such we can conclude that the kinetic data and analysis we report herein are indeed able to determine the main factors limiting the quantum efficiency of our photocatalytic system.

Scheme 2. Main processes and their time scales involved in the oxygen evolution reaction involving the RuP dye, the $\mathrm{Ru}^{\mathrm{IV}}=\mathrm{O}$ water oxidation catalyst and persulfate as sacrificial electron acceptor in a 7 -phbf solution. ( 1 ) $\mathrm{RuP}^{+}$ photogeneration. (2) Electron transfer between $\mathrm{RuP}^{+}$and the $\mathrm{Ru}^{\mathrm{IV}}=\mathrm{O}$ catalyst. (3) Initial dioxygen generation from water in the photoactivated system.

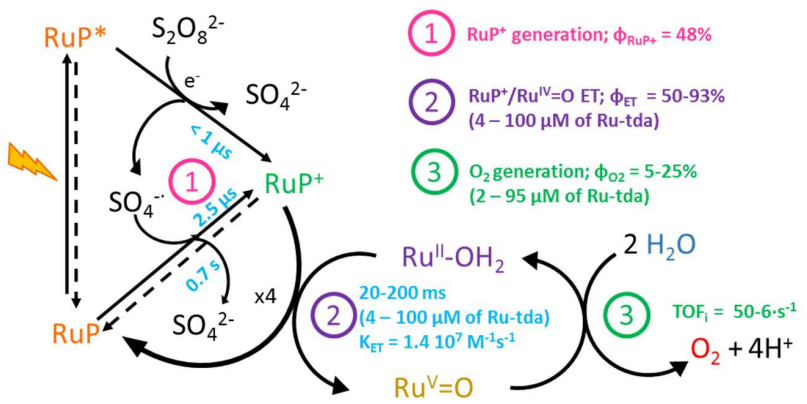

As has been discussed above, the measured quantum yield of $\mathrm{O}_{2}\left(\phi_{\mathrm{O}_{2}}\right)$ depends on the catalyst concentration (light blue trace Figure 6). We can assign this dependency to the increased efficiency of electron transfer between $\mathbf{R} \mathbf{u} \mathbf{P}^{+}$and $\mathbf{R} \mathbf{u}^{\mathrm{IV}}=\mathbf{O}$ with increasing catalyst concentration. (Compare violet trace with light and dark blue lines, Figure 6). This is related with the bimolecular nature of the process, with increasing the catalyst concentration enhancing the probability that $\mathbf{R u P}^{+}$species will oxidize a catalyst molecule rather than alternative oxidation substrates. This phenomena has been previously reported, but, the instability of the catalyst at high concentrations prevented the achievement of high efficiencies., $36,8 b, 9$. In the literature there are other examples showing that enhancing the interaction between the dye and the catalyst increases the quantum yields by favouring the dye-catalyst interaction. $5,6 \mathrm{a}, 8 \mathrm{a}$,Error! Bookmark not defined. In our system the stability of the RuP sensitizer is also improved by increased catalyst concentration (Figure S12). The susceptibility of the RuP to irreversible decomposition in its oxidized state has been reported previously, and is most likely associated with secondary oxidations of the bpy ligands. ${ }^{15}$ It is striking that for the photocatalytic system herein, the system stability is not limited by catalyst degradation but rather by degradation of the sensitizer and also by the increase in ionic strength and proton concentration during operation.

It is also apparent from Figure 6 that the largest quantum efficiency loss $(\sim 50 \%)$ results from inefficient $\mathbf{R u P}^{+}$ generation by the sacrificial electron donor $\mathrm{S}_{2} \mathrm{O}_{8}{ }^{2-}\left(\phi_{\mathrm{RuP}+}\right)$. Whereas in principle this sensitizer/donor system should yield two $\mathbf{R u P}^{+}$per photon, in practice inefficiencies in both oxidation reactions result in only $0.98 \mathrm{RuP}^{+}$per photon. We note that in principle this efficiency could be increased by higher $\mathrm{S}_{2} \mathrm{O}_{8}{ }^{2-}$ concentration, however in practice this resulted in lower oxygen yields, assigned to the resulting higher ionic strength and/or lower $\mathrm{pH}$, reducing the efficiency of catalyst oxidation by $\mathbf{R u} \mathbf{P}^{+}$. In addition at low catalyst concentrations, additional quantum efficiency losses result from inefficient catalyst oxidation by $\mathbf{R u P} \mathbf{P}^{+}$ $(\phi \mathrm{ET})$.Remarkably, the efficiency of this photoactivated system for oxygen generation is not limited by the catalyst activity, whereas by the photon flux and the generation of the $\mathbf{R u P}^{+}$. This analysis therefore clearly identifies that further advances in system performance will require focus on the sensitizer and sacrificial electron donor systems, rather than on improving catalyst turn over frequency. 


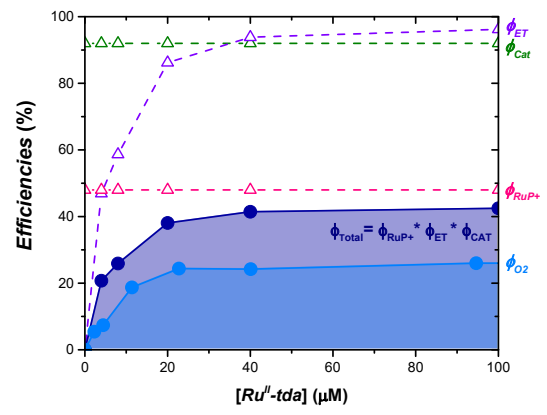

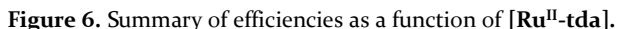
Dashed lines, estimated efficiencies for the individual processes: $\mathbf{R u P ^ { + }}$ generation $\left(\phi_{\mathrm{RuP}_{+}}\right)$(pink); Electron transfer between $\mathbf{R u P}+$ and $\mathbf{R} \mathbf{u}^{\mathrm{IV}}=\mathbf{O}$ accumulated in the steady state of the catalytic cycle $(\phi \mathrm{ET})$ (violet); Faradaic efficiency of $\mathbf{R u}^{\mathbf{I V}}=\mathbf{O}$ under electrocatalytic conditions ( $\left.\phi_{\text {CAT }}\right)$ (green). Solid lines, quantum yield efficiency estimated from: bulk oxygen generation $\left(\phi_{\mathrm{O}_{2}}\right)$ (light blue) and from spectroscopic experiments (Ф TOTAL) (dark blue).

The above discussion has focused on the chemical and quantum efficiencies of our photocatalytic system. We now turn to consideration of the rate of oxygen evolution. Whilst the $\mathbf{R u}^{\mathrm{IV}}=\mathbf{O}$ WOC is capable of a TOF of $8,000 \mathrm{~s}^{-1}$ when driven electrochemically, in the photocatalytic system reported herein, the photocatalytic TOF is in the range 6 - $50 \mathrm{~s} \mathrm{~s}^{-1}$ (determined as moles oxygen per second / moles of $\mathbf{R} \mathbf{u}^{\mathrm{IV}}=\mathbf{O}$, see supporting information for further details), increasing as the catalyst concentration is lowered. This photocatalytic TOF is clearly not limited by the $\mathbf{R} \mathbf{u}^{\mathbf{I V}}=\mathbf{O}$ WOC performance. Rather it will be determined by the flux of photons absorbed by the system, and by the quantum efficiency with which this system utilizes these absorbed photons to drive water oxidation. Under one sun irradiation, the absorbed photon flux is $0.17 \mu$ Moles s-1. Using the value for maximal oxygen evolution rate $\left(40 \mu \mathrm{M}\right.$ added $\mathbf{R} \mathbf{u}^{\mathrm{II}}$-tda, corresponding to $1.6 \mathrm{nMoles} \mathbf{R} \mathbf{u}^{\mathrm{IV}}=\mathbf{O}$ ), this absorbed photon flux should result in catalyst TOF of $22 \mathrm{~s}^{-1}$, compared to a measured TOF under these conditions of $13 \mathrm{~s}^{-1}$. These calculations confirm the final performance is mainly determined by the absorbed photon flux, with the difference between our measured and calculated TOF's indicating an additional loss pathway, discussed further below.

The absorbed photon flux limitation we observe herein reflects the limited light harvesting capability of our photocatalytic system. We note that increasing the sensitizer concentration will not substantially improve this, as over spectral range of absorption of the sensitizer, almost all photons are absorbed. The ratio of sensitizer per catalyst can be improved by lowering the catalyst concentration, but at the expense of lowering $\phi_{\mathrm{ET}}$, the efficiency of electron transfer from the oxidized sensitizer to the catalyst. This light harvesting limitation is addressed in photosynthetic organisms by the assembly of large antenna complexes (100's of molecular light absorbers) funneling excitation energy into each catalytic site. Our observation of that the effective TOF of our photocatalytic system is limited primarily by light harvesting efficiency is further evidence of the high performance of the molecular water oxidation catalyst employed herein.

The difference between our measured and calculated TOF's (and measured and calculated quantum efficiencies) suggests there is an additional efficiency loss not accounted for by our kinetic analysis. Most probably this results from our assumption that the catalytic efficiency of our photocatalytic efficiency $\left(\phi_{\mathrm{CAT}}\right.$, corresponding to the efficiency with which the $\mathbf{R} \mathbf{u}^{\mathbf{I V}}=\mathbf{O}$ oxidizes water rather than other substrates) is the same as the Faradaic efficiency previously measured for $\mathbf{R u}^{\mathbf{I V}}=\mathbf{O}$ electrocatalysis. ${ }^{2}$ Our photocatalytic system operates at a much lower catalyst TOF (between 6-50 s-1) than for the electrocatalytic system $\left(\mathrm{TOF}_{\max }=8\right.$, ooo s $\left.\mathrm{s}^{-1}\right)$, limited primarily by the flux of photons driving RuP oxidation, as discussed above. This mismatch in time scales between the photo- and electro-catalytic systems means that in the photocatalytic system each $\mathbf{R u}-\mathrm{H}_{2} \mathrm{O}$ oxidation state is required to be stable for much longer times before it is oxidized by the next $\mathbf{R u P}^{+}$molecule compared to the electrocatalytic system. This is likely to result in an effective lower faradaic efficiency in the photoactivated system due to undesired side reactions, which is a further potential area for future system optimization.

\section{CONCLUSIONS:}

Herein we have reported a remarkably efficient molecular photocatalytic system to photoxidize water to oxygen and undertaken a kinetic analysis of the factors determining system efficiency. At high concentrations of catalyst, the system operates with $25 \%$ quantum yield and $96 \%$ chemical efficiency, the highest reported to date for this type of photocatalytic system, attributed primarily favorable electron transfer and oxygen evolution kinetics. A high catalyst concentration is found to be required to optimize the efficiency of electron transfer between the oxidized sensitizer and the catalyst, which also has the effect of improving sensitizer stability. The main limitation to system quantum efficiency is found to be the relatively low efficiency of $\mathrm{S}_{2} \mathrm{O}_{8}{ }^{2-}$ as an electron scavenger to oxidize $\mathbf{R u P}$ * to $2 \mathbf{R u P} \mathbf{P}^{+}$, mainly due to competing back electron transfer to the $\mathbf{R u P}$ ground state. The overall rate of photocatalytic oxygen generation is found to be determined primarily by the incident photon flux. The $\mathbf{R u}^{\mathrm{IV}}=\mathbf{O}$ catalyst is found to be so robust and fast that neither the system efficiency nor lifetime are limited by its performance. As such we conclude that the performance of this remarkably efficient photocatalytic oxygen production system is limited not by the properties of the catalyst, but rather by the sensitizer and electron scavenger properties and by the incident photon flux.

\section{ASSOCIATED CONTENT}

Supporting Information. 
Experimental details, calculations of quantum yields, efficiencies and TOF. Additional UV-VIS, Cyclic voltammetries, quenching efficiencies, Transient Absorption Spectrocopy spectra and decays, Photoinduced Spectrocopy decays and oxygen detection measurements. All this information is available free of charge on the ACS Publications website.

\section{AUTHOR INFORMATION}

Corresponding Author

*Ifrancas@ic.ac.uk.

*allobet@iciq.cat

Present Addresses

†If an author's address is different than the one given in the affiliation line, this information may be included here.

Author Contributions
The manuscript was written through contributions of all authors. / All authors have given approval to the final version of the manuscript. / \$These authors contributed equally.

(match statement to author names with a symbol)

Funding Sources

Any funds used to support the research of the manuscript should be placed here (per journal style).

Notes

The authors declare no competing financial interests

\section{ACKNOWLEDGMENT}

Commented [FFL3]: Add your projects and fellowship

We acknowledge financial support from the European Research Council (project Intersolar 291482), L.F. thanks the EU for a Marie Curie fellowship (658270) and E.P. thanks the

Commented [FFL2]: Add your present addresses here
EPRSC for a DTP scholarship.

REFERENCES 
Insert Table of Contents artwork here

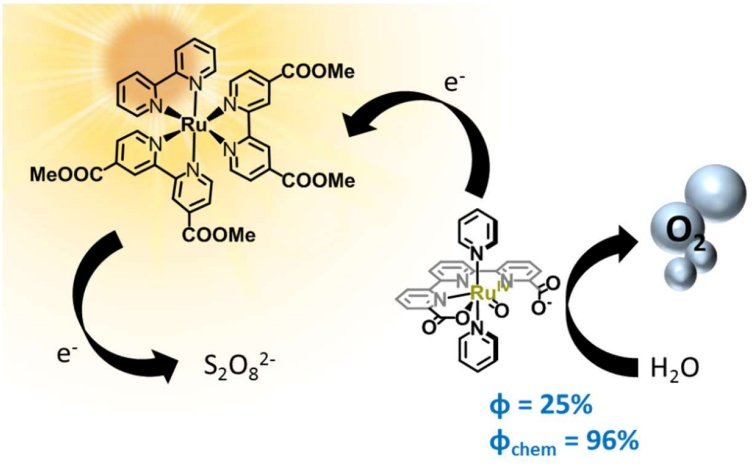

${ }^{1}$ (a) Sander, A. C.; Maji, S.; Francàs, L.; Böhnisch, T.; Dechert, S.; Llobet, A.; Meyer, F. ChemSusChem 2015, 8, 1697-1702. (b) GarridoBarros, P.; Funes-Ardoiz, I.; Drouet, S.; Benet-Buchholz, J.; Maseras, F.; Llobet, A. J. Am. Chem. Soc. 2015, 137, 6758-6761. (c) J. D. Blakemore, R. H. Crabtree and G. W. Brudvig, Chem. Rev. 2015, 115, 12974-13005 (d) Neudeck, S.; Maji, S.; López, I.; Meyer, S.; Meyer, F.; Llobet, A. J. Am. Chem. Soc. 2014, 136, 24-27. (e) Llobet, A. Molecular Water Oxidation Catalysis: A Key Topic for New Sustainable Energy Conversion Scheme, John Wiley \& Sons, Chichester, 2014.

${ }^{2}$ Matheu, R.; Ertem, M. Z.; Benet-Buchholz, J.; Coronado, E.; Batista, V. S.; Sala, X.; Llobet, A., J. Am. Chem. Soc. 2015, 137, 10786-10795.

${ }^{3}$ Lewandowska-Andralojc, A.; Polyansky, D. E.; Zong, R.; Thummel, R. P.; Fujita, E. Phys. Chem. Chem. Phys. 2013, 15, 14058 -14068.

${ }^{4}$ (a) Berardi, S.; Francàs, L.; Neudeck, S.; Maji, S.; Benet-Buchholz, J.; Meyer, F.; Llobet, A. ChemSusChem 2015, 8, 3688-3696. (b) Xu, Y.; Fischer, A.; Duan, L.; Tong, L.; Gabrielsson, E.; Åkermark, B.; Sun, L., Angew. Chem. Int. Ed. 2010, 49, 8934-8937. (c) Roeser, S.; Farràs, P.; Bozoglian, F.; Martínez-Belmonte, M. Benet-Buchholz, J.; Llobet, A. ChemSusChem 2011, 4, 197-207.( d) Laine, T. M.; Karkas, M. D.; Liao, R.-Z.; Akermark, T.; Lee, B.-L.; Karlsson, E. A.; Siegbahn, P. E. M.; Akermark, B. Chem. Commun. 2015, 51, 1862-1865. (e) Wang, L.; Duan, L.; Tong, L.; Sun, L. J. Catal. 2013, 306, 129-132.(f) Tong, L.; Wang, Y.; Duan, L.; Xu, Y.; Cheng, X.; Fischer, A.; Ahlquist, M. S. G.; Sun, L. Inorg. Chem. 2012, 51, 3388-3398. (g) Karlsson, E. A.; Lee, B.-L.; Åkermark, T.; Johnston, E. V.; Kärkäs, M. D.; Sun, J.; Hansson, Ö.; Bäckvall, J.-E.; Åkermark, B. Angew. Chem. Int. Ed. 2o11, 50, 11715-11718. (h) Xu, Y.; Fischer, A.; Duan, L.; Tong, L.; Gabrielsson, E.; Åkermark, B.; Sun, L. Angew. Chem. Int. Ed. 2010, 49, 8934-8937. (i) Xu, Y.; Duan, L.; Tong, L.; Akermark, B.; Sun, L., Chem. Commun. 2010, 46 (35), 6506-6508. (j) Duan, L.; Xu, Y.; Gorlov, M.; Tong, L.; Andersson, S.; Sun, L. Chem. Eur. J. 2010, 16, 4659-4668. (k) Besson, C.; Huang, Z.; Geletii, Y. V.; Lense, S.; Hardcastle, K. I.; Musaev, D. G.; Lian, T.; Proust, A.; Hill, C. L. Chem. Commun. 2010, 46, 2784-2786. (l) Duan, L.; Xu, Y.; Zhang, P.; Wang, M.; Sun, L. Inorg. Chem. 2010, 49, 209-215. (m)

${ }^{5}$ Li, H.; Li, F.; Zhang, B.; Zhou, X.; Yu, F.; Sun, L. J. Am. Chem. Soc. 2015, 137, 4332-4335

${ }^{6}$ (a) Geletii, Y. V.; Huang, Z.; Hou, Y.; Musaev, D. G.; Lian, T.; Hill, C. L. J. Am. Chem. Soc. 20o9, 131, 7522-7523. (b) Huang, Z.; Geletii, Y. V.; Musaev, D. G.; Hill, C. L.; Lian, T. Ind. Eng. Chem. Res. 2012, 51, 11850-11859. (c) Kaledin, A. L.; Huang, Z.; Geletii, Y. V.; Lian, T.; Hill, C. L.; Musaev, D. G. J. Phys. Chem. A 2010, 114, 73-80.

7 (a) Natali, M.; Orlandi, M.; Berardi, S.; Campagna, S.; Bonchio, M.; Sartorel, A.; Scandola, F. Inorg. Chem. 2012, 51, 7324-7331. (b) La Ganga, G.; Puntoriero, F.; Campagna, S.; Bazzan, I.; Berardi, S.; Bonchio, M.; Sartorel, A.; Natali, M.; Scandola, F. Farad. Discuss. 2012, 155, 177-190.

${ }^{8}$ (a) Orlandi, M.; Argazzi, R.; Sartorel, A.; Carraro, M.; Scorrano, G.; Bonchio, M.; Scandola, F. Chem. Commun. 2o1o, 46, 3152-3154. (b) Pizzolato, E.; Natali, M.; Posocco, B.; Montellano Lopez, A.; Bazzan, I.; Di Valentin, M.; Galloni, P.; Conte, V.; Bonchio, M.; Scandola, F.; Sartorel, A. Chem. Commun. 2013, 49, 9941-9943.

9 (a) Song, F.; Ding, Y.; Ma, B.; Wang, C.; Wang, Q.; Du, X.; Fu, S.; Song, J. Energy Environ. Sci. 2013, 6, 1170-1184. (b) Han, X.-B.; Zhang, Z.-M.; Zhang, T.; Li, Y.-G.; Lin, W.; You, W.; Su, Z.-M.; Wang, E.-B. J. Am. Chem. Soc. 2014, 136, 5359-5366.

${ }^{10}$ (a) Car, P.-E.; Guttentag, M.; Baldridge, K. K.; Alberto, R.; Patzke, G. R. Green Chem. 2012, 14, 1680-1688. (b) Kaveevivitchai, N.; Chitta, R.; Zong, R.; El Ojaimi, M.; Thummel, R. P. J. Am. Chem. Soc. 2012, 134, 10721-10724. 
${ }^{11}$ Lv, H.; Song, J.; Geletii, Y. V.; Vickers, J. W.; Sumliner, J. M.; Musaev, D. G.; Kögerler, P.; Zhuk, P. F.; Bacsa, J.; Zhu, G.; Hill, C. L. J. Am. Chem. Soc. 2014, 136, 9268-9271.

${ }^{12}$ Parent, A. R.; Crabtree, R. H.; Brudvig, G. W. Chem. Soc. Rev. 2013, 42, 2247-2252.

${ }^{13}$ (a) Henbest, K.; Douglas, P.; Garley, M. S.; Mills, A. J. Photochem. Photobiol. 1994, 8o, 299-305. (b) White, H. S.; Becker, W. G.; Bard, A. J. J. Phys. Chem. 1984, 88, 1840-1846.

${ }^{14}$ Rybak, W.; Haim, A.; Netzel, T. L.; Sutin, N. J. Phys. Chem. 1981, 85, 2856-2860.

${ }^{15}$ (a) Ghosh, P. K.; Brunschwig, B. S.; Chou, M.; Creutz, C.; Sutin, N. J. Am. Chem. Soc. 1984, 106, 4772-4783. (b) Limburg, B.; Bouwman, E.; Bonnet, S. ACS Catal. 2016, 6, 5273-5284.

16 (a) Romain, S.; Bozoglian, F.; Sala, X.; Llobet, A. J. Am. Chem. Soc. 2009, 131, 2768-2769. (b) Bozoglian, F.; Romain, S.; Ertem, M. Z.; Todorova, T. K.; Sens, C.; Mola, J.; Rodríguez, M.; Romero, I.; Benet-Buchholz, J.; Fontrodona, X.; Cramer, C. J.; Gagliardi, L.; Llobet, A. J. Am. Chem. Soc. 2009, 131, 15176-15187. 